\title{
Treatment of a Superficial Mycosis by Low-temperature Plasma: A Case Report
}

Michaela Švarcová1, Jaroslav Julák ${ }^{2}, V^{\prime}$ í Hubka ${ }^{3}$, Hana Soušková',
Vladimír Scholtz ${ }^{4}$
${ }^{1}$ Department of Computing and Control Engineering, Faculty of Chemical Engineering, Institute of Chemical Technology in Prague, Prague, Czech Republic; ${ }^{2}$ Institute of Immunology and Microbiology, First Faculty of Medicine, Charles University in Prague and General University Hospital in Prague, Prague, Czech Republic;

${ }^{3}$ Department of Botany, Faculty of Science, Charles University in Prague, Prague, Czech Republic;

${ }^{4}$ Department of Physics and Measurements, Faculty of Chemical Engineering, Institute of Chemical Technology in Prague, Prague, Czech Republic

Received November 15, 2013 ; Accepted April 4, 2014.

Key words: Dermatomycosis - Trichophyton - Low-temperature plasma Cometary discharge

Abstract: A case of dermatomycosis caused by zoophilic strain of Trichophyton interdigitale was treated by low-temperature plasma produced by direct current (DC) cometary discharge. The shortening of skin lesion persistence along with suppression of subjective discomfort and etiological agent was observed.

This study was supported by Neuron Fund for Support of Science.

Mailing Address: Assoc. Prof. RNDr. Jaroslav Julák, PhD., Institute of Immunology and Microbiology, First Faculty of Medicine, Charles University in Prague and General University Hospital in Prague, Studničkova 7, 12800 Prague 2, Czech Republic; e-mail: jaroslav.julak@lf1.cuni.cz 


\section{Introduction}

The rapidly developing field of low-temperature (or non-thermal) plasma use in medical applications has previously been reviewed by several authors, e.g. by Laroussi $(2005,2009)$, Moreau et al. (2008), Kong et al. (2009), Ehlbeck et al. (2011), Laroussi et al. (2012) or Isbary et al. (2013a). The biological effects of plasma are mediated by plenty of reactive particles, such as reactive oxygen species (ROS) and reactive nitrogen species (RNS), for a review, see Graves (2012).Till present, the plasma was mostly produced in air by dielectric barrier discharges, gliding arc, plasma jets and various corona discharges. The medical applications include mainly decontamination, disinfection and sterilization of various surfaces and liquids, studies concerning the chronic wound healing (Isbary et al., 2013b) or cancer treatment (Schlegel et al., 2013) also appeared. The microbicidal effect of plasma was studied mainly on bacteria, but suppression of fungi (yeasts and moulds) in vitro was also reported (Scholtz, 2005; Julák et al., 2011; Soušková et al., 2011, 2012; Sláma et al., 2013).

In previous papers (Scholtz and Julák, 2010a, b), we reported a new type of jetlike point-to-point DC electric discharge produced in atmospheric air and named the cometary discharge. Its efficiency was improved by inserting an electrically insulated metallic grid between the discharge and the exposed object, as described in Julák and Scholtz (2013) and Scholtz et al. (2013). Here, we describe an attempt to adopt this discharge for treatment of a case of dermatomycosis.

\section{Case presentation}

Patient is a 20 -year-old woman student, living on a farm in a village near Prague. She was in daily contact with farm animals, including rabbits, dogs and cats. One day she observed itching and tonus in skin on the upper left quadrant of chest, the second day a circular lesion of efflorescence appeared, becoming next day red and conspicuous; this stage was denoted here as day 0 . The lesion had elevated edge with numerous pinpoint pustules (tinea corporis, "ringworm"). Because she worked during her studies on biological applications of low-temperature plasma, she decided on her own risk not to consult a physician, but treated this efflorescence by self-medication using the cometary discharge. Smears were taken from the leading edge and central area of the affected site with a dry tampon; samples were also taken using the bacteriological loop and sterile toothbrush, but this appeared to be less effective. Samples were applied onto Sabouraud dextrose agar plate (SDA, Oxoid), where the culture of a mould appeared after 5 days of cultivation at $25^{\circ} \mathrm{C}$.

This mould was identified as zoophilic strain of Trichophyton interdigitale (note: such isolates were traditionally identified as $T$. mentagrophytes according to the older taxonomy) due to light brown, granular colonies with dark brown reverse on SDA, presence of numerous macroconidia and spiral hyphae in culture. The identification was verified by the DNA sequencing of the ITS rDNA. This region 
was $100 \%$ identical with T. interdigitale subtype III (FM986758) (Heidemann et al., 2010). The isolates belonging to this subtype are considered to be of animal origin (the broad spectrum of the hosts comprise cats, dogs, guinea pigs, rabbits, etc.). The DNA isolation technique, PCR condition and sequencing were described previously (Hubka and Kolařik, 2012). The sequence of the ITS region and partial LSU rDNA was deposited into the EMBL database under the accession number HG793054. The isolate is deposited in the Culture Collection of Fungi at the Department of Botany of Charles University in Prague as CCF 4707.

The treatment started after smears intake on day 0 . It consisted in application of low-temperature plasma produced by cometary discharge with inserted grid at $9 \mathrm{kV}$ and $150 \mu \mathrm{A}$, the distance between the discharge tip and the grid was $1 \mathrm{~cm}$; the same distance was maintained between the discharge and the exposed skin. This treatment was applied for 10 minutes every day on the inner half of the lesion, its other half was left untreated as a control. On the $2^{\text {nd }}$ day, white tips appeared on the pimples within the whole area, the exposed part of the efflorescence started to flake off on the $5^{\text {th }}$ day. On the $8^{\text {th }}$ day, the itching of the exposed area becomes perceptible lower, it disappeared almost and completely on the $10^{\text {th }}$ and $14^{\text {th }}$ day, respectively; itching persisted on the unexposed site. Starting the $11^{\text {th }}$ day, the efflorescence in the unexposed area diffused to axilla, whereas in the exposed area continued scaling and no new pimples appeared. On $19^{\text {th }}$ day, the skin in the
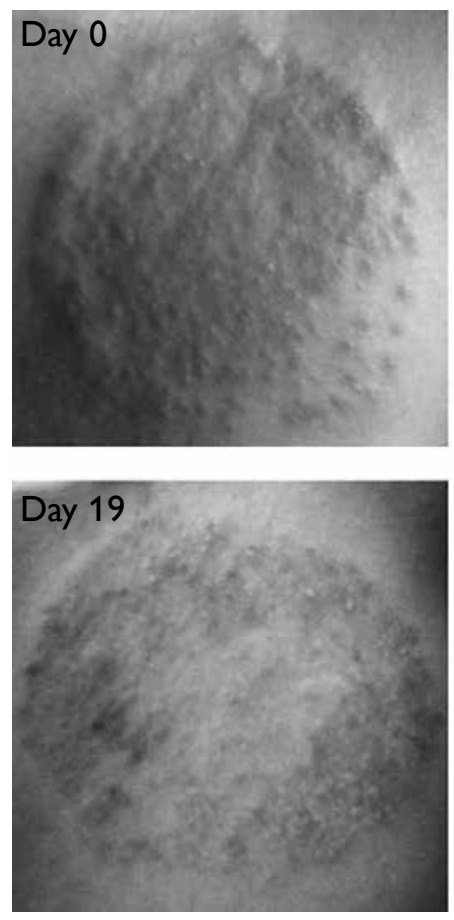
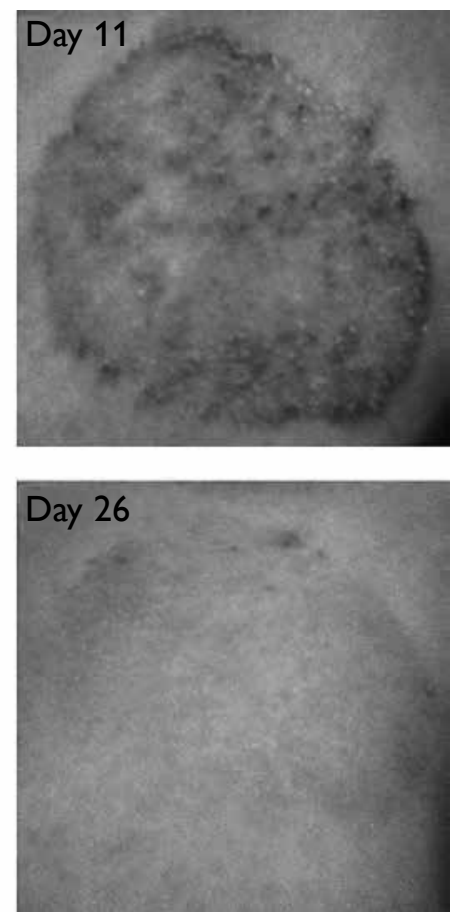

Figure 1 - The appearance of the efflorescence before treatment (upper left), during treatment (upper right and lower left) and after treatment (lower right). On all pictures, the left half of lesion was exposed to discharge. 
Table 1 - Number of Trichophyton colonies (colony forming units) found on exposed and unexposed sites during treatment

\begin{tabular}{ccc}
\hline Day & Exposed & Unexposed \\
\hline 0 & - & 48 \\
5 & 26 & 50 \\
9 & 5 & 250 \\
14 & 3 & 7 \\
19 & 0 & 5 \\
26 & 0 & 0 \\
\hline
\end{tabular}

exposed site was reddish and dusky but smooth-surfaced with no pimples and itching, which persisted in the unexposed site. The treatment was finished on the $24^{\text {th }}$ day, when the exposed area remains unchanged, whereas in the unexposed area some isolated pustules persisted. Figure 1 documents the appearance of the lesion during treatment.

Control smears were taken from the lesion during treatment and processed as above. The results are summarized in Table 1, where the numbers of colonies grown on agar from samples taken from exposed and unexposed sites at various days of treatment are compared.

Smears were also taken from the fur and skin of domestic animals living on the farm. Numerous fungi were found, but none of them can be attributed to the genus Trichophyton.

\section{Discussion}

The in vitro resistance of fungi to low-temperature plasma is comparatively high and differs substantially among various genera. E.g. Cladosporium sphaerospermum in suspension is inactivated within 15 min of exposure, whereas Penicilium crustosum needs more than 20 min and Aspergillus oryzae was not completely inactivated even after $30 \mathrm{~min}$. Yeast Candida albicans is more susceptible, being quenched within 6 minutes, whereas bacteria need only 2-4 minutes (Soušková et al., 2011). Unfortunately, the sensitivity of dermatophytes, including Trichophyton spp., was not yet studied in vitro.

In this case of benign but annoying dermatomycosis, the suppression of subjective discomfort was observed after $8^{\text {th }}$ to $10^{\text {th }}$ day of treatment, whereas it persisted for more than 20 days without treatment. The presence of etiological agent was lowered markedly during the initial stages and disappeared completely before 19 days of treatment. The spontaneous healing occurred, but markedly later than in treated area of efflorescence. The source of infection was not found.

The treatment of skin with low-temperature plasma represents no harm for the exposed persons, as documented by numerous studies, e.g. Julák and Scholtz (2013) or Lademann et al. (2013). 


\section{References}

Ehlbeck, J., Schnabel, U., Polak, M., Winter, J., von Woedtke, Th., Brandenburg, R., von dem Hagen, T., Weltmann, K.-D. (2011) Low temperature atmospheric pressure plasma sources for microbial decontamination. J. Phys. D Appl. Phys. 44, 013002.

Graves, D. B. (2012) The emerging role of reactive oxygen and nitrogen species in redox biology and some implications for plasma applications to medicine and biology. J. Phys. D Appl. Phys. 45, 263001.

Heidemann, S., Monod, M., Gräser,Y. (2010) Signature polymorphisms in the internal transcribed spacer region relevant for the differentiation of zoophilic and anthropophilic strains of Trichophyton interdigitale and other species of T. mentagrophytes sensu lato. Br. J. Dermatol. 162, 282-295.

Hubka,V., Kolařík, M. (2012) $\beta$-tubulin paralogue tubC is frequently misidentified as the benA gene in Aspergillus section Nigri taxonomy: primer specificity testing and taxonomic consequences. Persoonia 29, $1-10$.

Isbary, G., Zimmermann, J. L., Shimizu, T., Li, Y.-F., Morfill, G. E., Thomas, H. M., Steffes, B., Heinlin, J., Karrer, S., Stolz, W. (2013a) Non-thermal plasma - More than five years of clinical experience. Clinical Plasma Medicine 1, 19-23.

Isbary, G., Stolz, W., Shimizu, T., Monetti, R., Bunk,W., Schmidt, H.-U., Morfill, G. E., Klämpfl, T. G., Steffes, B., Thomas, H. M., Heinlin, J., Karrer, S., Landthaler, M., Zimmermann, J. L. (2013b) Cold atmospheric argon plasma treatment may accelerate wound healing in chronic wounds: Results of an open retrospective randomized controlled study in vivo. Clinical Plasma Medicine 1, 25-30.

Julák, J., Scholtz, V. (2013) Decontamination of human skin by low-temperature plasma produced by cometary discharge. Clinical Plasma Medicine 1, 31-34.

Julák, J., Pazlarová, J., Savická, D., Scholtz, V., Soušková, H. (2011) Fungicidal effect of corona discharge. Mykol. Listy 115, 28-36. (in Czech)

Kong, M. G., Kroesen, G., Morfill, G., Nosenko, T., Shimizu, T., van Dijk, J., Zimmerman, J. L. (2009) Plasma medicine: an introductory review. New J. Phys. 11, 115012.

Lademann, J., Ulrich, C., Patzelt, A., Richter, H., Kluschke, F., Klebes, M., Lademann, O., Kramer, A., Weltmann, K. D., Lange-Asschenfeldt, B. (2013) Risk assessment of the application of tissue-tolerable plasma on human skin. Clinical Plasma Medicine 1, 5-10.

Laroussi, M. (2005) Low temperature plasma-based sterilization: overview and state-of-the-art. Plasma Process. Polym. 2, 391-400.

Laroussi, M. (2009) Low-temperature plasmas for medicine? IEEE Trans. Plasma Sci. 37, 714-725.

Laroussi, M., Kong, M. G., Morfill, G., Stolz, W. (2012) Plasma Medicine. Cambridge University Press, Cambridge.

Moreau, M., Orange, N., Feuilloley, M. G. J. (2008) Non-thermal plasma technologies: new tools for bio-decontamination. Biotechnol. Adv. 26, 610-617.

Schlegel, J., Köritzer, J., Boxhammer, V. (2013) Plasma in cancer treatment. Clinical Plasma Medicine 1, 2-7.

Scholtz, V. (2005) Corona discharge influence on micro-organisms. Probl. Atom. Sci. Tech. 10, 190-191.

Scholtz, V., Julák, J. (2010a) The "cometary" discharge, a possible new type of DC electric discharge in air at atmospheric pressure, and its bactericidal properties. J. Phys. Conf. Ser. 223, 012005.

Scholtz, V., Julák, J. (2010b) Plasma jet-like point-to-point electrical discharge in air and its bactericidal properties. IEEE Trans. Plasma Sci. 38, 1978-1980.

Scholtz, V., Kvasničková, E., Julák, J. (2013) Microbial inactivation by electric discharge with metallic grid. Acta Phys. Polon. A 124, 62-65.

Sláma, J., Kříha, V., Julák, J., Fantová, V. (2013) Comparison of dielectric barrier discharge modes fungicidal effect on Candida albicans growth. Probl. Atom. Sci. Tech. 83, 237-239. 
Soušková, H., Scholtz, V., Julák, J., Kommová, L., Savická, D., Pazlarová, J. (2011) The survival of micromycetes and yeasts under the low-temperature plasma generated in electrical discharge. Folia Microbiol. (Praha) 56, 77-79.

Soušková, H., Scholtz, V., Julák, J., Savická, D. (2012) The fungal spores survival under the low-temperature plasma. In: Plasma for Bio-decontamination, Medicine and Food Security. Hensel, K., Machala, Z., Akishev, Y., Pp. 57-66, Springer, Dordrecht. 